\title{
Vacina contra rotavírus
}

\section{Vaccine against rotavirus}

Correspondência | Correspondence:

Secretaria de Estado da Saúde de São Paulo

Av. Dr. Arnaldo, $3511^{\circ}$ andar sala 135

01246-901 São Paulo, SP, Brasil

E-mail: agencia@saude.sp.gov.br

Texto de difusão técnico-científica da

Secretaria de Estado da Saúde de São Paulo.

\author{
Divisão de Imunização e Divisão de Doenças de Transmissão \\ H ídrica e Alimentar. Centro de Vigilância Epidemiológica "Prof. \\ Alexandre Vranjac". Coordenadoria de Controle de Doenças. \\ Secretaria de Estado da Saúde de São Paulo
}

O rotavírus é um vírus da família Reoviridae que causa diarréia grave, freqüentemente acompanhada de febre e vômito. É, hoje, considerado um dos mais importantes agentes causadores de gastroenterites e óbitos em crianças menores de cinco anos, em todo o mundo. A maioria das crianças se infecta nos primeiros anos de vida, porém os casos mais graves ocorrem principalmente em crianças até dois anos de idade. Em adultos é mais rara, tendo sido relatados surtos em espaços fechados, como escolas, ambientes de trabalho e hospitais.

Até o momento, são reconhecidos sete diferentes grupos de rotavírus, designados de $\mathrm{A}$ a $\mathrm{G}$. Os rotavírus do grupo A destacam-se como os de maior importância epidemiológica. O vírus contém no genoma o RNA fragmentado de dupla cadeia, que sintetiza proteínas não estruturais (persistem apenas na morfogênese viral) e as proteínas estruturais: VP1, VP2 e VP3 componentes do core viral e VP7 (glicoproteína G) e VP4 (proteína $\mathrm{P}$, sensível à protease) na camada externa. As duas últimas constituem os maiores antígenos envolvidos na neutralização viral e são responsáveis pela definição dos diferentes sorotipos.

Encontram-se descritos 10 sorotipos de VP7 e oito

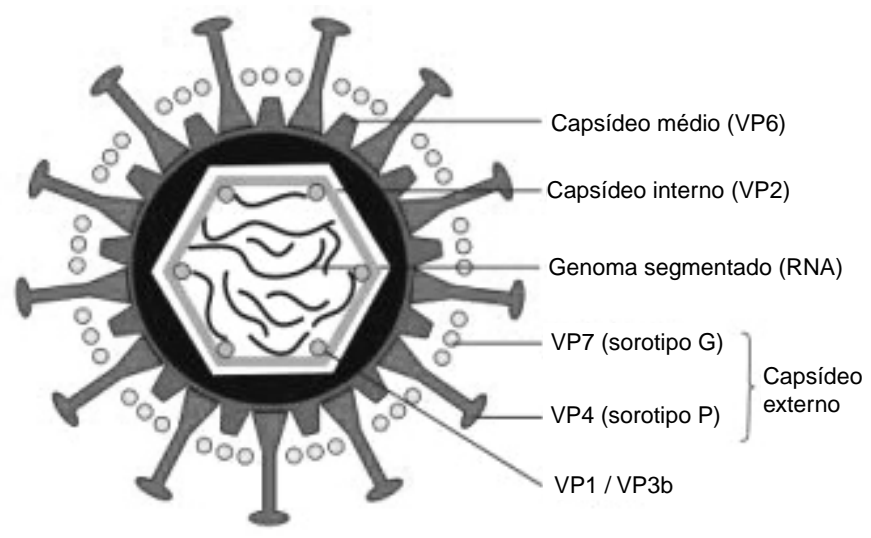

Figura - Adaptada de Cunliffe et al, Lancet 2002;359:640-2. de VP4 capazes de infectar o homem, com possibilidade teórica de 80 combinações. Os sorotipos G1P[8], G2P[4], G3P[8], G4P[8] e G9P[8] ocorrem com maior frequiência no mundo todo, dentre estes a cepa G1P[8] é a predominante. A cepa G9 tem emergido desde os anos 1990 e predomina em algumas regiões. No Estado de São Paulo, observou-se também a circulação do G12.

A doença apresenta curto período de incubação, com início abrupto, vômitos em mais de $50 \%$ dos casos, febre alta e diarréia profusa, culminando em grande parte dos casos com desidratação. $\mathrm{O}$ uso do soro de reidratação oral tem-se revelado altamente eficaz no combate à desidratação destes casos.

A transmissão é fecal-oral (alta excreção nas fezes um trilhão de partículas virais/ml de fezes), por água ou alimentos, por contato pessoa a pessoa, objetos contaminados e, provavelmente, também por secreções respiratórias. A sazonalidade das infecções, estendendo-se desde o outono até a primavera, é observada nos países de clima temperado. Nas regiões tropicais as infecções ocorrem o ano todo.

O elevado potencial disseminador e a grande variedade de cepas circulantes do rotavírus, favorecidos por fatores como o clima, conglomerados urbanos de alta densidade populacional, convivência em creches e outros ambientes fechados, mostram que, além das medidas tradicionais de higiene e de saneamento básico para sua prevenção, a perspectiva real para o seu controle seria a introdução de uma vacina eficaz e segura no calendário de vacinação infantil.

A introdução da vacina no calendário nacional está prevista para março de 2006 e atenderá a crianças nascidas a cada ano, a partir dos dois meses de idade. 


\section{Situação epidemiológica}

No mundo cerca de 125 milhões de episódios diarréicos por rotavírus ocorrem globalmente a cada ano, causando entre 600.000 a 870.000 óbitos. Estima-se que no Brasil a taxa média de diarréia em crianças menores de três anos de idade seja de 2,5 episódios por criança/ano, das quais $10 \%(0,25)$ se associam aos rotavírus. Em 2003, de acordo com os dados do Datasus, ocorreram 269.195 internações por diarréia em crianças menores de cinco anos. Considerando-se que 34\% destas internações associam-se aos rotavírus, é plausível estimar que, em 2003, ocorreram 91.526 internações por esse agente infeccioso.

A partir da implantação no Estado de São Paulo, em 1999, da vigilância da doença diarréica, por meio do programa de Monitorização da Doença Diarréica Aguda (MDDA) e de outros sistemas complementares, tem sido possível estimar a incidência da diarréia e, ao mesmo tempo, detectar surtos e epidemias por doenças veiculadas por água e alimentos. Os dados quantitativos de diarréia por município, coletados pelo programa, permitem também estruturar outros estudos para conhecer a etiologia das diarréias.

Os surtos de rotavírus têm sido freqüentemente detectados pelo programa de MDDA, a partir da investigação do aumento de casos de diarréia nas semanas epidemiológicas. $\mathrm{O}$ aumento de surtos por rotavírus pode ser observado ao longo do tempo, mesmo considerando a maior sensibilidade do sistema de vigilância em captação das diarréias. Em 1999, entre o total de surtos de diarréia com etiologia identificada, $7,7 \%$ correspondiam a surtos de rotavírus; em 2004, mais de $20 \%$ dos surtos foram por este agente.

Para determinar a incidência da gastroenterite por rotavírus e conhecer seu impacto na população, o Centro de Vigilância Epidemiológica "Prof. Alexandre Vranjac", em conjunto com outras entidades, desenvolveu uma pesquisa sobre a diarréia por rotavírus em menores de cinco anos, nos municípios de Rio Claro, no interior do Estado, e Guarulhos, na Grande São Paulo, no período de 17 de fevereiro de 2004 a 16 de fevereiro de 2005.

Os resultados mostraram que diarréias por rotavírus representaram entre $6,5 \%$ a $17,9 \%$ do total das diarréias, com coeficientes de incidência de 6,6 e 16,3 casos de rotavírus por mil crianças menores de cinco anos, em Rio Claro e Guarulhos, respectivamente. Por sua vez, o coeficiente de incidência da diarréia aguda por diversas etiologias foi de 91,1 casos por mil crianças menores de cinco anos em Guarulhos e 101,7, em Rio Claro.

Utilizando as faixas de variação dos indicadores construídos e extrapolando-os para o Estado de São Paulo, estimou-se que possam ocorrer de 22.000 a 55.000 casos de rotavírus entre as mais de 300.000 diarréias agudas por diversas etiologias, e que o vírus é responsável por 26.000 a 70.000 consultas médicas/ano em ambulatórios, serviços de emergência e hospital.

Em Guarulhos, houve predominância dos genótipos G9P[8], tendo sido detectado um novo genótipo circulante, o G12. Em Rio Claro, observou-se a predominância do G1P[8]. Tendências a serem monitoradas ao longo do tempo e importantes para a avaliação da introdução da vacina como medida de prevenção.

O custo anual estimado causado pela diarréia por rotavírus no Estado de São Paulo é maior que US\$ 1 milhão.

Estes resultados indicaram que o rotavírus é um importante agente causador de diarréia entre os menores de cinco anos, reforçando a necessidade de melhores estratégias de prevenção, tais como a introdução de vacina no calendário infantil para diminuição dos danos e custos da doença. A introdução desta nova vacina no calendário básico, certamente, contribuirá para a redução dos casos de diarréia por rotavírus.

\section{Vacinas contra rotavírus}

As vacinas de primeira geração contra rotavírus, desenvolvidas no início da década de 1980, foram de origem animal (bovina e símia). A grande variabilidade nos resultados dos estudos de campo atribuiu-se ao fato dessas vacinas não oferecerem proteção contra os sorotipos epidemiologicamente mais importantes.

As vacinas de segunda geração foram de natureza antigênica polivalente e com rearranjo genético, na tentativa de ampliar a proteção contra os sorotipos G1 a G4. A primeira foi licenciada nos Estados Unidos, em 1998. Era uma vacina oral, atenuada, tetravalente, com rearranjo símio e humano, aplicada no esquema de três doses aos dois, quatro e seis meses de idade. A sua utilização foi suspensa em julho de 1999, após a aplicação de cerca de 1,2 milhões de doses em 600 mil lactentes, devido ao aumento de casos de invaginação intestinal.

Em 2000 teve início um estudo com uma outra vaci- 
na oral atenuada, a RIX4414, na Finlândia, de origem humana, com elevada imunogenicidade, eficácia e segurança.

Há, ainda, estudos publicados que utilizam uma vacina oral atenuada pentavalente, com rearranjo humano-bovino, G1, G2, G3, G4 e P[8], também com elevada proteção para as formas graves de diarréia. A redução de hospitalização, após a terceira dose para os sorotipos G1-G4 foi de 94,5\% (IC 95\%:91,2-96,6), a eficácia para qualquer gravidade de diarréia foi de 74,0\% (IC 95\%:66,8-79,9) e a eficácia para diarréia grave foi de 98,0\% (IC 95\%: 88,3-100). Entretanto, não se observou risco aumentado para a ocorrência de invaginação intestinal.

Dentre outras vacinas contra rotavírus em estudo no mundo destacam-se: a multivalente de rearranjo bovino e humano e a RV3. Na China, desde 2000, utiliza-se uma vacina monovalente de origem de cepa de carneiro.

\section{Composição da vacina}

A vacina contra rotavírus será incluída no calendário brasileiro em março de 2006. É uma vacina oral, atenuada, monovalente (G1P1A[8]), cepa RIX4414. Cada dose da vacina oral contra rotavírus contém:

- Frasco com pó liofilizado:

- no mínimo $10^{6,0} \mathrm{CCID50}$ da cepa vacinal

- sacarose 9mg, dextrana $18 \mathrm{mg}$, sorbitol 13,5 mg, aminoácidos $9 \mathrm{mg}$ e meio Eagle modificado por Dulbecco (DMEM) 3,7mg.

- Aplicador com diluente:

- carbonato de cálcio $80 \mathrm{mg}$, goma de xantana $3,5 \mathrm{mg}$, água para injeção $1,3 \mathrm{ml}$.

Após a reconstituição cada dose corresponde a $1 \mathrm{ml}$.

\section{Estudos de eficácia}

Dos estudos de eficácia da vacina, participaram lactentes entre 6 e 13 semanas de idade de 11 países da América Latina, incluindo o Brasil (Belém/PA). Do total de lactentes, 10.159 receberam a vacina e 10.010 , placebo.

A eficácia na prevenção de diarréia grave foi de $84,7 \%$ (IC 95\%:71,7-92,4), para hospitalização 85\% (IC 95\%:69,6-93,5). A eficácia para prevenção de diarréia grave, incluindo todos os sorotipos do grupo $\mathrm{G}$, foi de 91,8\% (IC 95\%:74,1-98,4). Para os sorotipos G3P[8], G4P[8] e G9P [8] foi de 87,3\% (IC 95\%:64,196,7 ) e para o sorotipo G2P[4] foi menor, $41,0 \%$ (IC
95\%:-79,2-82,4). A proteção tem início cerca de duas semanas após a segunda dose.

\section{Esquema vacinal, idade mínima e máxima e intervalo entre as doses}

O esquema vacinal recomendado é de duas doses, aos dois e quatro meses de idade, simultaneamente com as vacinas Tetravalente (DTP/Hib) e Sabin. O intervalo mínimo entre as duas doses é de quatro semanas.

Para esta vacina algumas restrições são recomendadas:

- Para a aplicação da primeira dose:

- Deve ser aplicada aos dois meses de idade;

- Idade mínima de um mês e 15 dias de vida (seis semanas);

- Idade máxima de três meses e 15 dias de vida (14 semanas).

- Para a aplicação da segunda dose:

- Deve ser aplicada aos quatro meses de idade;

- Idade mínima de três meses e 15 dias de vida (14 semanas);

- Idade máxima de cinco meses e 15 dias de vida (24 semanas).

A vacina não deve, de forma alguma, ser aplicada fora destes prazos. Nos estudos realizados com as novas vacinas contra rotavírus, considerando-se o risco aumentado de invaginação intestinal em relação à idade de aplicação observada com a vacina suspensa em 1999, como precaução, não foram aplicadas em situações fora das faixas etárias estabelecidas.

Se ocorrer esta situação, preencher a ficha de Notificação de Procedimentos Inadequado e acompanhar a criança por 42 dias. Na vigência de eventos adversos, preencher a ficha de Notificação de Eventos Adversos.

\section{Precauções na administração da vacina}

- Não repetir a dose se a criança vomitar ou regurgitar.

- Nenhuma dose aplicada fora dos prazos recomendados poderá ser repetida. Nessas situações, como precaução, a criança deverá ser acompanhada ambulatorialmente por 42 dias, para afastar a possibilidade de ocorrência de eventos adversos. Preencher ficha de Notificação de Procedimento Inadequado e Ficha de Notificação de Eventos Adversos, se for o caso.

- A vacina não está contra-indicada para lactentes que convivam com pacientes imunodeprimidos ou gestantes.

- Não há restrições quanto ao consumo de líquidos 
ou alimentos, inclusive leite materno, antes ou depois da vacinação.

- Filhos de mães HIV+ poderão ser vacinados, desde que não apresentem manifestações clínicas graves ou imunossupressão.

\section{Situações em que se recomenda o adiamento da vacinação}

- Durante a evolução de doenças agudas febris graves, sobretudo para que seus sinais e sintomas não sejam atribuídos ou confundidos com possíveis efeitos adversos da vacina.

- Crianças com diarréia que necessitam de hospitalização.

\section{Contra-indicações:}

- Imunodeficiência congênita ou adquirida.

- Uso de corticosteróides em doses elevadas (equivalente a $2 \mathrm{mg} / \mathrm{kg} / \mathrm{dia}$ ou mais, por mais de duas semanas), ou submetidas a outras terapêuticas imunossupressoras (quimioterapia, radioterapia).

- Reação alérgica grave a um dos componentes da vacina ou em dose anterior (urticária disseminada, broncoespasmo, laringoespasmo, choque anafilático), até duas horas após a aplicação da vacina.

- História de doença gastrointestinal crônica.

- Malformação congênita do trato digestivo.

- História prévia de invaginação intestinal.

\section{Vacinação simultânea}

A vacina oral contra rotavírus poderá ser aplicada simultaneamente com as vacinas: DTP, DTPa (acelular), Hib, Hepatite B, Pneumococo 7-valente e Salk, sem prejuízo das respostas das vacinas aplicadas. Até o momento, não há experiência acumulada com a aplicação simultânea de vacina contra o meningococo.

A maioria dos estudos utilizou a aplicação da vacina com 15 dias de intervalo com a vacina oral contra poliomielite, indicando boa resposta para ambos imunobiológicos. Estudos realizados com a administração simultânea da vacina rotavírus e vacina oral contra poliomielite apresentaram redução na resposta de anticorpos IgA para a primeira dose de rotavírus. Após a aplicação da segunda dose não houve prejuí- zo da imunogenicidade. Portanto, não ocorrendo a administração simultânea, deve-se respeitar o intervalo de 15 dias entre as doses.

\section{Eventos adversos}

Nos estudos de segurança realizados as incidências de febre, diarréia, vômitos, irritabilidade, tosse ou coriza não foram diferentes entre o grupo vacinado e o grupo que recebeu placebo. No entanto, considerando a implantação da nova vacina, recomenda-se a notificação nas seguintes situações:

- reação alérgica sistêmica grave (até duas horas da administração da vacina);

- presença de sangue nas fezes até 42 dias após a vacinação;

- internação por abdome agudo obstrutivo até 42 dias após a aplicação.

Nas situações de reação alérgica e internação por abdome agudo obstrutivo, solicita-se a notificação imediata à Central do CVE, pelo telefone 08000555466.

\section{Invaginação intestinal}

É uma forma de obstrução intestinal na qual um segmento do intestino invagina sobre o outro segmento, localizado mais distalmente, causando obstrução intestinal e compressão vascular da alça invaginada. Tem maior ocorrência em crianças entre quatro e nove meses de idade, sendo uma das causas mais freqüentes de abdômen agudo nesta faixa etária. O lactente apresenta náusea, vômitos, dor abdominal e, às vezes, pode apresentar fezes com muco e sangue ("geléia de morango"). O tratamento pode ser conservador, no entanto, em algumas situações, o tratamento cirúrgico é indicado.

Para avaliar o risco de invaginação intestinal com a nova vacina, foram acompanhados 63.225 lactentes sadios em 11 países da América Latina e na Finlândia, dos quais 31.673 receberam as duas doses da vacina e 31.552 receberam placebo. Nos 30 dias subseqüentes à vacinação ocorreram 13 casos de invaginação: seis no grupo que recebeu a vacina e sete no grupo placebo ( $R R=0,85$; IC 95\%: 0,30-2,42). Não se encontrou risco aumentado de invaginação intestinal no grupo vacinado. 